\title{
OPTIMIZATION OF DAYLIGHT IN MUSUEMS AND ART GALLERIES
}

\author{
Ar. Kirti Varandani ${ }^{1}$, Ar.Vibhuti Joshi ${ }^{2}$, Ar. Sangeeth S Pillai ${ }^{3}$ \\ ${ }^{1} P G$ Student (M.Des,Sustainable design, Scholar CODE,VGU), \\ ${ }^{2}$ Assistant Professor (CODE, VGU) \\ ,3Malaviya National Institute of Technology \\ 1,2,3Jaipur, Rajasthan, (India).
}

Article DOI: https://doi.org/10.36713/epra7327

DOI No: 10.36713/epra7327

\begin{abstract}
The aim of research is to identify the connection between daylight and museums. A museum may be a place where individuals will explore and learn the past, present and future of history, culture and science. Nowadays museum architecture emphasizes the museum for public interaction and best for education approach. The museum lighting is a challenge with daylight openings. This paper analyses the lighting environment of museum and art galleries with a satisfactory solution of daylight by using different passive design strategies without avoiding the harm to the artifacts and these parameters are good lighting solutions for existing as well as proposed building in terms of sustainability, energy consumption and perseveration. By using these parameters, we can also manage the artificial light and provide an advance solution in LED technologies and lighting solutions can be effectively used to retrofit a museum lighting environment and affecting the connection to the environment.

Considering the benefits and challenges of introducing the daylight in museums and galleries. The typology of building and daylight parameters have directly impact on environment and create a visual shape in visitor's mind.

This study is based on majority of heritage buildings current deterioration state prevents those buildings from performing efficiently. A sustainable reuse approach for heritage buildings is considered essential. Old palaces that are usually reused with different functions mostly like museums for their considered interior beauty and unique rich designs. Function alteration along with a deteriorated state augments the energy consumption problem. The optimization of various skylight parameters is evaluated for their combined performance. The results disclose an improved performance which indicates the effectiveness of the energy and day lighting optimized strategies and techniques for heritage reuse. Daylight will help to create building more live, and a step to reducing the climate change and save our environment with global warming.
\end{abstract}

KEYWORDS: Museums; Daylight Factor; Passive Design Strategies; Visual Comfort; Thermal Comfort; Sustainability.

\section{INTRODUCTION}

Museums are public buildings where the artifacts are displayed in different modes to entertain and enrich visitors. (Hooper Greenhill, 2013). In museum light plays different roles and enhance the space. But the main concern of daylight is control its penetration into the space. The availability of daylight is to excess the daylight level distribution in the space by managing the artificial light. And the other challenge to understand the effect of light composition and its combination.

\subsection{BACKGROUND STUDY}

Natural lighting system become more important as some time museums and galleries have witnessed numerous upgrades to them. As private collections 


\section{EPRA International Journal of Research and Development (IJRD)}

Volume: 6 | Issue: 6 | June 2021

- Peer Reviewed Journal

of the elite, exhibition halls and various art galleries have relocated nearer to the public space from their predominantly 18th century origins, being increasingly supportive and pluralistic in nature. [A Practical Guide for Sustainable Climate Control and Lighting in Museums and Galleries Revision Finals.] In the late 1950 s there was subsequent economic boom, new structures were intended to meet the developing urban culture's new necessities. This brought a large amount of conventional houses being demolished and substituted by new buildings that could allow productive and versatile spaces. Later on, the authorities perceived the meaning of these structures in representing the identity of the region and accordingly implemented regulations to retain the essential ones. In this way, a few of these average UAE structures have been transformed into galleries and their rooms have been utilized as display spaces. Nonetheless, these conventional structures were not initially planned or worked as galleries. In the exhibition hall rooms, numerous issues were set up, for example, the presence of serious daylight and expanded measures of illuminance that could hurt the items and construct an unfortunate visual climate. [Daylighting performance in UAE traditional buildings used as museums, 2018] In the twentieth Century, the emphasis of exhibition halls has changed from being internally centered on preserving and conserving collections to an outward emphasis on setting up zones of mass allure, discourse, interest, and display. These days, exhibition halls and exhibitions, as iconic architecture, may become showcases and attractors themselves, the achievement of which is mostly calculated in terms of occupancy numbers, produced tourism and revenue. In this sense, "manageability" is relevant, and "proper environment control and lighting conditions" are causing exhibition halls and displays specifically a great deal of outrage lately. [A Practical Guide for Sustainable Climate Control and Lighting in Museums and Galleries Revision Finals].

\subsection{RAJASTHAN SCENARIO}

Structures are the users of electricity, representing in excess of $33 \%$ of all energy consumption and just about $30 \%$ of fossil fuel byproducts. The construction industry represents around 35 percent of the general energy consumption in our country. Transport and manufacturing firms are probably the biggest users of petroleum products. Nonetheless, their development plays a significant role in mitigating global warming. This is the reason the World Business Council for Sustainable Development (WBCSD) delivered the Energy effectiveness in Buildings (EEB) project. Executing energy effectiveness activities in Jaipur business area will bring about in general energy reserve funds of 6.3 billion kilowatt-hours in FY2014-15, which is around $30 \%$ of the complete power utilization of Rajasthan state in 2014-15.The The residential and industrial users accounted for most of electrical energy burned-through for the duration of the period of time. There will be a 7 percent intensified expansion in energy prerequisite of the business area before the finish of the Thirteenth Plan (2018-2022). [EEB Laboratory Jaipur].

Rajasthan became the first state in India to inform the Energy Conservation Building Code in 2011 of a contract requirement of $120 \mathrm{KVA}$ or more for all buildings with a linked load of 100 $\mathrm{KW}$ or more, or of a 500 sq.mt or more compact area used for commercial purposes. [EEB Laboratory Jaipur]

\begin{tabular}{|c|c|c|c|}
\hline \multirow[t]{2}{*}{ CATEOORY } & \multirow[t]{2}{*}{ ENEASYYCONSUUMPTDN IMU] } & \multicolumn{2}{|c|}{ ENERGY SAVINES:PDTENTIALAS PER STUDY } \\
\hline & & Percentage & Mu \\
\hline Domistic & $1587,23(96 \%)$ & 20\%: & 317,40 \\
\hline Commerial & 803.98 2.24\% & 1996 & 152.57 \\
\hline Public Streer Lights: & $76.14\{29\}$ & $75 \%$ & 57.105 \\
\hline Public Water Works & $111.6,(390)$ & 2096 & 22.32 \\
\hline trndusiries & $838.38(259)$ & $10 \%$ & 83.83 \\
\hline TOTAL & 3417391 & & te3ams: \\
\hline
\end{tabular}

\section{Need of study}

Today, artificial lighting has overtaken the natural lighting. There is a need to understand significance of light in setting of work of art just as the visual quality in exhibition halls. Analyzing the role of the sunlight, which is a significant job towards the supportability of workmanship in museums and art

\section{ures could reduce energy consumption}

galleries that is in the high demand and will further help in energy savings and benefitting the natural environment. The effect of the types of window openings and the connection with the climate, advantages and concerns of daylight in museums and art galleries is needed to be analyzed. From an architectural and design point of view, daylight 
holds an important role as it is the part that give the space more value and enhance the visual and thermal quality of space. A person judges a building on the basis of its aesthetic, uniqueness, and its silent features which we can say its visual quality, thermal quality, openings, connectivity etc. when we talk about daylight in Rajasthan than it is the place where we see the maximum clear sunny days and Rajasthan is well known for its monuments and heritage. The selection of the topic and the place are connected to each other. There are lots of museums and arts galleries are available in Rajasthan. But everyone wants to work on artificial light as an architect and designer it's our responsibility to aware the people towards sustainability. Sun is one of the natural resources helps us to reduce the energy consumption of electricity and light plays an important role in museum, in place of maximum use of artificial light we can use daylight at some spaces by using daylight design strategies. In museum there are so many creative structures, artwork, a collection of artifacts and different objects of creative, cultural, historical, or scientific importance which gives various artist and historical knowledge, lights give a vital role of interaction with human with the place. Lights not only lighten up the space but also reveal the art of exhibit.

Now a day's artificial light is most common way to achieve the demand but with this we can indirectly increase the heat and temperature of our surroundings. Causes the global warming, by using daylight in museum and optimizing the artificial light we can give our contribution and it's a foundation step towards sustainability. Which will help to reduce carbon footprints and with this step we can make our building more energy efficient, sustainable and more economical. As we know that it has different benefits and drawbacks of according to the climatic condition. With the help of daylight in museum to control global warming and heat this step will also help to reduce energy consumption and co 2 emission.

\subsection{DAYLIGHT AND HEALTH}

Daylight have a multiple advantage. It is a main source of light before artificial lighting become reliable and affordable. It has a solar radiation which is visible to human eye emitted by sun and perceived during day time. In Rajasthan the availability of the clear sun is maximum according to the previous studies and it cannot be artificially replicated often referred to as natural light. Characteristic light impacts the human framework and physiology in numerous regards. This investigation basically analyzes and explains the roundabout effect of common light. This is concerned chiefly with natural eye and how light effects it and maturing. Light has capacities on both amount and quality levels, particularly quality which has a significant job. [Tawfik, A. W. M. A. (2005).]

'Light is maybe the most critical ecological contribution, after food, in controlling substantial capacities'. Sunshine has gotten a "structural" apparatus, in what elements of day like enlightenment, change of light as the day goes through its course, and so on and are supplanted by electrical lighting arrangements. During the day, light gives an assortment of choice and upgrades. The expanded efficiency from getting sunlight can help pressure decline and may likewise build profitability.

Sunshine is the radiation, noticeable to the natural eye that has been delivered from the sun and afterward acquired longer than a day. At the point when the world Health Organization gave a report. on wellbeing, it depicted wellbeing as "a condition of complete physical, mental and social prosperity and not simply the presence or nonappearance of sickness or illness." The hour of sunshine applies a significant impact on our wellbeing. For wellbeing, we likewise need to focus on the sun; even daylight is imperative for our environment. A large portion of the illuminating presences (or star-like lights) are made in the yellow-green range of light since it gives the most noteworthy luminance. The best sort of light source is the full range light as it gets a wide scope of daylight like light that makes an enormous band of light. Sunshine lights give splendid light yield near 100\%.

\subsection{LITERATURE REVIEW}

As per study a good number of buildings are lacking in term of visual conditions and comfort because mostly are focused on functions and structure. But in term of environment it will be compromised at some point. Many studies investigated daylight in museums and art galleries using qualitative literature case study of existing building. Light plays a major role in assessing the artwork's appeal. It is now understood that the light on the artwork should be about three times as bright or intense as the ambient light. Although, as art objects are susceptible to sun, infrared (IR) and ultraviolet (UV) radiation, they should be discouraged. Direct sunlight can exceed more than 30,000 lux (luminous flux per unit area) and is therefore not recommended for use in lightsensitive artworks under any conditions, as it contributes to damage. Studies have shown that the highest suitable exposures for painting are 30 foot candles (ftc, non-SI unit of luminance or light intensity) equal to 325 lux. Light is one of the most critical and powerful elements in museums and galleries. The purpose of light in art galleries and 


\section{EPRA International Journal of Research and Development (IJRD)}

Volume: 6 | Issue: 6 | June 2021

- Peer Reviewed Journal

museums is not only to make it easier for visitors to see the work, but also to maintain the masterpiece. Galleries are also one of the most complex styles of buildings to be illuminated by daylight. Most galleries and museums prefer a louvered top lighting system; skylight as it is the great idea to provide light source. [Worpole, $\mathrm{K}$. (2000).].

Planning for daylight isn't just a matter of heavy use of window glass, but there can be problems of uncomfortable glare. Daylight planning should be an important part of building design. A design strategy to validate good daylight conditions in art museums considers daylight availability, sky conditions, building location, street obstruction/ visual connection to the outside, efficiency and shape of the building, interior planning and design, window and facade design (size and divisions of the windows), creative daylight strategies and checking the design strategy. Innovative light-control methods include louvres and light racks, rotating curtains, reflectors, prismatic glazing and pipes. Architecture elements, such as facade arrangement, space arrangement and lighting system, must be optimized to effectively lightcontrol a building. [Kaya, S. M., \& Afacan, Y. (2018)]

The daylight issue could be a common and simple method used to measure the standards of daylight in a room/building under an overcast sky.

Table 1: Average daylight factor

\begin{tabular}{|c|c|c|}
\hline Average Df & Appearance & Energy Implications \\
\hline$<2 \%$ & Room Looks & Electric Lighting Needed \\
& Gloomy & Most Of The Day \\
\hline $2 \%-5 \%$ & Predominantly & Good Balance Between \\
& Day Lit & Lighting And Thermal \\
& Appearance & Aspects \\
\hline
\end{tabular}

Table 2: Minimum Daylight Factors

\begin{tabular}{|c|c|}
\hline Types of space & Daylight factor(\%) \\
\hline $\begin{array}{c}\text { Art galleries, museums and } \\
\text { studios }\end{array}$ & $4-5$ \\
\hline
\end{tabular}

Table 3: Average Illumination Level

\begin{tabular}{|c|c|}
\hline Spaces & Illumination(lux) \\
\hline Museum and galleries & 300 \\
\hline Workshop & $100-400$ (general) \\
\cline { 2 - 2 } & $300-400$ (task) \\
\hline Halls and exhibitions & $500-1000$ \\
\hline
\end{tabular}

\subsection{OPTIMIZED VISUAL} EXPERIENCE OF ARTWORK

The nature of light in museums contains a solid effect on the tourist's insight and experience. The experience of artefacts under natural light will be more comfortable and good than just under unnatural lighting. Moreover, due to the always changing nature of light, the visitors experience is extraordinary during their each and every visit. The main component that the tourist needs when seeing displays are: purity of the art (for figures) and exactness of item color (for artworks, drawings). The use of sunlight can give a good degree of visual solace in the space and consider visual sense, as keeps up the natural feeling in their authentic way as they use to be.

The sunlight will improve the uniqueness of the art by creating shades to them. Sunlight provides with shade, color rendering of the exhibits which can't be done by artificial methods. Due to its persistent range, brightening from sunlight gives impartial shading enlistment to all color tones. Despite the fact that of the difference in the amount of sunlight, the natural eye can adjust to the progressions and keep an exact view of the item's color. Besides, for a large number day lighting empowers the guest to notice them as near the lighting conditions as those under which they were made. Particularly in paintings, sunlight can help to show the authenticity of the art without changing the fine art's tones. 


\section{EPRA International Journal of Research and Development (IJRD)}

\subsection{SUSTAINABILITY}

Sunlight is one of the essential source of renewable energy and its utilization in plan assumes a fundamental part in the sustainability of the structures. The dissemination of sunlight in museum is a vital technique for green design, as the utilization of electrical lighting inside every show and different zones will represent 200 th of the structure's energy utilization. Later on, the utilization of daylight mix with artificial light and lighting control frameworks will definitely improve the energy adequacy of galleries.

\subsection{THERMAL COMFORT}

A literature study of indoor natural conditions found that thermal comfort is ranked by building inhabitants to be of more worthy or significance than be visual and acoustic solace and have indoor air quality. [Frontczak et al., 2012] In any case, while having a look at museum or exhibition hall, the biggest effect on the fulfillment for guests are, DOORNBOS, M. the technique for display, visual and locomotor openness, enlightenment and rest zones. [Jeong and Lee, 2006].

Power utilization for lighting is an inefficient and energy consuming cycle. Since individuals in many created nations use power, it generally affects energy utilization, there are numerous valid justifications for trying to build up a lighting design in building interiors that is viable, effective and harmless to the ecosystem without harming the climate. Energy protection through daylight integration to interior spaces is inevitable. It is additionally a perplexing issue on the grounds that the ecological necessities for the protection of the materials force exacting principles to maintain a strategic distance from the weakening of displays. It is conceivable to have subjective daylight design with productive visual solace and save energy effectively without harming the presentation objects within art museums. Hence, art museums ought to be qualified with bioclimatic, ecological benevolent and energy cognizant design. A productive and sustainable exhibition hall building design can completely meet the compositional, useful, solace, control and wellbeing prerequisites, by additionally providing revolutionary measures of energy savings and providing decrease of carbon dioxide outflows.

\subsection{ENVIRONMENTAL BENEFITS}

Buildings use energy to warm, cool, light, ventilate and fix utilizations in internal territories. In most industrialized nations the energy used by buildings by and large address around $50 \%$ of all out energy utilization. Energy comes from the burning of petroleum derivatives. Buildings are answerable for roughly $50 \%$ of $\mathrm{CO} 2$ emanations into the environment. What's more, in light of these burning there is additionally $10 \%$ of methane outflows, $25 \%$ of Nox emanations and $25 \%$ of SOx discharges. Consequently, buildings are a significant effect of overall warming, environmental change, air contamination and corrosive rains. Beside the subjective meaning of daylight for people and engineering, environmental points of daylight integration are pivotal for sustainable lighting design. Daylight without squander use provided through its design is promptly accessible and is harmless to the ecosystem additionally cost free. Daylight utilization there is a less contamination and less mischief on climate. Consequently, daylight utilization is additionally valuable for our current circumstance. Within the art museums, this is additionally extremely helpful in light of the fact that this suggests personal satisfaction will be increased in where museums are found and this will prompt decrease of contamination of the art gallery buildings and improvement of the indoor environment.

\section{INFERENCES}

With reference to the studies, there were recognizable and quick changes in the sunlight due to climate conditions. Albeit these progressions were obvious on the whole exhibitions, in the rooms that just have toplighting openings these varieties fill in as another layer in the impression of the craftsmanship showed. The varieties make the experience of both the space and workmanship more intriguing as changes in light power, give various impressions of the room and feature various shades of the artworks. In request to guarantee the best utilization of light and dodge direct daylight in the exhibitions; it is additionally the underlying advance to practical plan. The direction of the openings and their relationship with the way of the sun, influences the amount, quality and dispersion of light.

Windows are the most well-known type of daylighting utilized in many sorts of structures, as they give light, view and ventilation. In exhibition halls, they have been utilized verifiably in numerous displays, yet fundamentally in light of the fact that the gallery work was given to existing structures. Window gaps permit normal light to the inside of a space, yet can likewise give a perspective on the outside climate. They can catch perspectives to the metropolitan settings or nature around the 


\section{EPRA International Journal of Research and Development (IJRD)}

Volume: 6 | Issue: 6 | June 2021

structure; in some cases, even utilize this view as a system for the craftsmanship showed.

There are two fundamental ways that sunlight openings communicate with the outside; either by making a visual association with the outside climate (metropolitan environmental factors or sky) or by framing an association with the elements of common light associated with time and climate conditions. By acquiring a view to the outside, in this manner a connection to the sunlight changes is additionally settled.

\section{CONCLUSION}

The significance of natural light in the museums. Artificial light is a shortcut to enlighten our creative spaces but natural light can be used as a sustainable methodology for the museums. As per study I have analyzed that Lighting in museum is essential but on the other hand can also cause deterioration of the sculptures or the exhibits. Light is not just a requirement but serves as a medium for use to provide a context with the historic times in exhibitions. The intensity of light and the duration of exposure are the main factors that can lead to the destruction or can benefit the users as well as the historic artifacts. Lighting parameters and the source of lighting is most essential component to be looked upon while designing a museum. From the design point of view, climate of a place is also important to understand and design the museum according to it. So, need of the hour is to balance a relation between the climatic condition of the place i.e. environmental conditions and design of the museums and galleries to achieve the sunlight to the best possible way. Therefore, day lighting in museums with the co-relation of climatic conditions should be further studied to frame design guidelines for day lighting in museums, the sustainability and passive solar daylighting strategies for museum building in context of Rajasthan.

\section{REFERENCES}

1. Ahmad, N., Ahmad, S. S., Talib, A., \& Yaman, R. (2017). Visual Responses of Visitors towards Daylighting in Museums: A case study of Malaysia. PERTANIKA JOURNAL OF SOCIAL SCIENCE AND HUMANITIES, 25, 323-332

2. Ajmat, R., Sandoval, J., Arana Sema, F., O'Donell, B., Gor, S., \& Alonso, H. (2011). Lighting design in museums: exhibition vs. preservation. WIT Transactions on The Built Environment, 118, 195-206

3. Al-Maiyah, S., \& Elkadi, H. (2015). Turkish Dlight: accentuating heritage values with daylight. Proceedings of the Institution of Civil EngineersEngineering History and Heritage, 168(4), 139-149.

4. Al-Sallal, K. A., AbouElhamd, A. R., \& Dalmouk, M. $B$. (2018). UAE heritage buildings converted into museums: Evaluation of daylighting effectiveness and potential risks on artifacts and visual comfort. Energy and Buildings, 176, 333-359.

5. Ameer Mustafa Varzgani 2014-15

6. A Practical Guide for Sustainable Climate Control and Lighting in Museums and Galleries Revision Finalsm

7. Aries, M. B., Aarts, M. P., \& van Hoof, J. (2015). Daylight and health: A review of the evidence and consequences for the built environment. Lighting Research \& Technology, 47(1), 6-27

8. Balocco, C., \& Volante, G. (2018). Lighting design for energy sustainability, information, and perception. A museum environment as a case study. Sustainability, 10(5), 1671.

9. BEE-ECBC guidelines 2017

10. Davidson, L. (2013). Visitor studies: Toward a culture of reflective practice and critical museology for the visitor-centered museum. The international handbooks of museum studies, 503-527

11. Daylighting performance in UAE traditional buildings used as museums, 2018

12. de Oliveira, F. S., \& Guedes, M. C. (2006). Daylighting museums-a case study in Lisbon. In PLEA2006-The 23rd Conference on Passive and Low Energy Architecture

13. EEB Laboratory Jaipur

14. Fathy, F., Mansour, Y., Sabry, H., Refat, M., \& Wagdy, A. (2020). Conceptual framework for daylighting and facade design in museums and exhibition spaces. Solar Energy, 204, 673-682

15. Garside, D., Curran, K., Korenberg, C., MacDonald, L., Teunissen, K., \& Robson, S. (2017). How is museum lighting selected? An insight into current practice in UK museums. Journal of the Institute of Conservation, 40(1), 3-14.

16. International Council of Museums (ICOM)-2007

17. https://multicomfort.saint-gobain.com/comforts-andsolutions/visual-comfort.

18. https://www.wbdg.org/resources/daylighting

19. https://www.energy.gov/energysaver/save-electricityand-fuel/lighting-choices-save-you-money/daylighting

20. https://mahaurja.com/meda/data/energy_conservation /pdf/EC_needec.pdf

21. https://sigearth.com/the-benefits-of-daylighting-inyour-building/ https://doi.org/10.1177/1420326X17704028

23. Hurlbert, A., \& Cuttle, C. (2020). New museum lighting for people and paintings

24. Hunt, E. G. (2009). Study of museum lighting and design.

25. Illuminating Engineering Society, IES RP-31-14, Recommended Practice for the Economic Analysis of Lighting. New York: IESNA, 2014.

26. Importance of Daylight In Art Galleries Ameer Mustafa Varzgani(2015)

27. Iordanidou,C.(2017).Daylight openings in art museum galleries:A link between art and the outdoor environment (Dissertation). Retrieved from http://urn.kb.se/resolve?urn=urn:nbn:se:kth:d iva$\underline{215338}$

28. Kaja, N. (2015). An Overview of Energy Sector in India. International Journal of Science and Research (IJSR), 6.

29. Kaya, S. M., \& Afacan, Y. (2018). Effects of daylight 


\section{EPRA International Journal of Research and Development (IJRD)}

design features on visitor's satisfaction of museums. Indoor and Built Environment, 27(10), 1341-1356.

30. Kim, C. S., \& Chung, S. J. (2011). Daylighting simulation as an architectural design process in museums installed with toplights. Building and Environment, 46(1), 210-222.

31. Kreps, C. F. (2008). Appropriate museology in theory and practice. Museum Management and Curatorship, 23(1), 23-41.

32. Kristinsdóttir, A. (2017). Toward sustainable museum education practices: confronting challenges and uncertainties. Museum Management and Curatorship, 32(5), 424-439.

33. Licht, F. G. (2000). Good Lighting for Museums, Galleries and Exhibitions 18.

34. McCall, V., \& Gray, C. (2014). Museums and the 'new museology': theory, practice and organisational change. Museum Management and Curatorship, 29(1), 19-35.

35. Oliveira, F., \& Steemers, K. (2008). 210: Daylighting Museums-a survey on the behaviour and satisfaction of visitors. In PLEA 2008-25th Conference on Passive and Low Energy Architecture.

36. P. Hanselaer, C. Lootens, W.R. Ryckaert, D. Deconinck and P.b Rombauts, "Power density targets for efficient lighting of interior task areas," Lighting, Research \& Technology, vol. 39 (2), pp. 171-184, 2007.

37. Piana, E. A., \& Merli, F. (2020, October). Lighting of Museums and Art Galleries. In Journal of Physics: Conference Series (Vol. 1655, No. 1, p. 012138). IOP Publishing.

38. Pinilla, S. M., Moliní, D. V., Fernández-Balbuena, A. Á., Raboso, G. H., Herráez, J. A., Azcutia, M., \& Botella, Á. G. (2016). Advanced daylighting evaluation applied to cultural heritage buildings and museums: Application to the cloister of Santa Maria El Paular. Renewable Energy, 85, 1362-1370.

39. Reinhart, Christoph (2014). Daylighting Handbook 1. Christoph Reinhart. ISBN 9780692203637

40. Schielke, T. (2020). Interpreting art with light:
Museum lighting between objectivity and hyperrealism. LEUKOS, 16(1), 7-24.

41. Sterrett, J., \& Piantavigna, R. (2018). Building an Environmentally Sustainable San Francisco Museum of Modern Art. Studies in Conservation, 63(sup1), 242-250.

42. Subramanian, C. V., \& Kamalesvari,S.(2016).Daylight and Sustainable Architecture for Warm Humid climate. Mirror (glass), 80, 90

43. Tawfik, A. W. M. A. (2005). Natural Lighting As A Factor In Providing A Healthy Environment In Buildings (Doctoral Dissertation, Faculty of Engineering at Cairo University In Partial Fulfillment of the Requirements for the Degree of Masters Of Science In Architecture Faculty Of Engineering, Cairo University Giza).

44. Ulas, E. B., \& Roos, M. (2013). Looking at Art in a New light.

45. Users' Manual - Bureau of Energy Efficiency

46. Vaezizadeh, F., \& Kazemzade, M. (2013). Investigating different strategies for light and ventilation provision in vernacular underground architecture and their integration with underground museums architecture-a case study in Iran. International Journal on Technical and Physical Problems of Engineering, 5(4), 63-71.

47. Wilson, M. (2006). Lighting in museums: lighting interventions during the European demonstration project 'Energy efficiency and sustainability in retrofitted and new museum buildings'(NNES-199920). International Journal of Sustainable Energy, 25(3-4), 153-169.

48. Wolfgang Schone, Berlin 1993

49. Worpole, K. (2000). Here comes the sun: architecture and public space in twentieth-century European culture. Reaktion Books.

50. Zannis, G., Santamouris, M., Geros, V., Karatasou, S., Pavlou, K., \& Assimakopoulos, M. N. (2006). Energy efficiency in retrofitted and new museum buildings in Europe. International Journal of Sustainable Energy. 